\title{
Corrigendum: Exploring Limited Capacity in the Grid: Actors, Problems, and Solutions
}

\author{
Jenny Palm * \\ International Institute for Industrial Environmental Economics, Lund University, Lund, Sweden
}

Keywords: power grid, electricity system, lack of capacity, user flexibility, stakeholder, actor

\section{OPEN ACCESS}

Edited and reviewed by:

Frontiers in Energy Research,

Frontiers Media SA, Switzerland

*Correspondence:

Jenny Palm

jenny.palm@iiiee.lu.se

Specialty section: This article was submitted to

Smart Grids,

a section of the journal

Frontiers in Energy Research

Received: 28 September 2021

Accepted: 29 September 2021

Published: 14 October 2021

Citation:

Palm J (2021) Corrigendum: Exploring Limited Capacity in the Grid: Actors,

Problems, and Solutions.

Front. Energy Res. 9:785205.

doi: 10.3389/fenrg.2021.785205

\section{A Corrigendum on:}

Exploring Limited Capacity in the Grid: Actors, Problems, and Solutions. Palm J (2021). Front. Energy Res. 9:663769. doi:10.3389/fenrg.2021.663769

In the original article, there was an error in the Funding statement. The original statement was "This work was supported by the Kamprad Family Foundation and the Horizon project NEWCOMERS under the Grant No. 837753." The correct statement is "This work was supported by the Kamprad Family Foundation and the Horizon project NEWCOMERS under the Grant No. 837752."

The authors apologize for this error and state that this does not change the scientific conclusions of the article in any way. The original article has been updated.

Conflict of Interest: The author declares that the research was conducted in the absence of any commercial or financial relationships that could be construed as a potential conflict of interest.

Publisher's Note: All claims expressed in this article are solely those of the authors and do not necessarily represent those of their affiliated organizations, or those of the publisher, the editors and the reviewers. Any product that may be evaluated in this article, or claim that may be made by its manufacturer, is not guaranteed or endorsed by the publisher.

Copyright $(2021$ Palm. This is an open-access article distributed under the terms of the Creative Commons Attribution License (CC BY). The use, distribution or reproduction in other forums is permitted, provided the original author(s) and the copyright owner(s) are credited and that the original publication in this journal is cited, in accordance with accepted academic practice. No use, distribution or reproduction is permitted which does not comply with these terms. 